\title{
Verb Doubling in Turkish: Data from Trabzon Dialect
}

\author{
Hande Sevgi*
}

\begin{abstract}
This study investigates the phenomenon of verb doubling in Trabzon dialect of Turkish. Based on similarities and differences between verb doubling in Trabzon Turkish and other languages, this paper identifies the structural properties of verb doubling in Trabzon Turkish in order to provide a representation of the structure within the minimalist framework (Chomsky, 1993). Following Harizanov and Gribanova's (2017) analysis on Russian clefts, I claim that this structure can be analyzed via the presence of two different movement processes in the structure: focus related movement in narrow syntax, and post-syntactic head movement.
\end{abstract}

Keywords. Trabzon Turkish; verb doubling; contrastive focus; movement processes

1. Introduction. A specific structure which bears similar properties with verb doubling phenomena in other languages is used in some dialects of Turkish spoken in Trabzon, a city on the Black Sea coast of northeastern Turkey: language

(1) Context: A: How did you go there, did you drive?

B: I went there by walking.

Yürü-me yürü-dü-m.

walk-MA walk-PST-1SG

'I walked.'

This structure (henceforth, VDbl) is interpreted with emphasis on the meaning of the action defined by the verb (Coşar, 2015). As the translation of the sentence indicates, it contributes a contrastive meaning in the context of denial of a statement that is uttered previously. Moreover, $\mathrm{VDbl}$ is not acceptable in out-of-blue contexts.

$\mathrm{VDbl}$ is very common in the daily conversations of speakers of Trabzon Turkish (Coşar, 2015: 248). However, this structure is marginal and considered unacceptable for speakers of other dialects. Coşar (2015) investigates VDbl in Trabzon dialect and identifies this structure as 'double verb 'constructions. She argues that VDbl shows similarities with some structures used in Old Anatolian Turkish. Moreover, she claims that this similarity indicates that Trabzon dialect carries some archaic features of Turkic languages.

(2) Old Anatolian Turkish (Adapted from Coşar, 2015; 248)

kov kov-la

gossip gossip-VBZ

'to gossip'

(3) Uyghur (Adapted from Coşar, 2015; 248)

sakınç sakın-

thought think

'to be lost in thoughts'

\footnotetext{
* I would like to thank Zeynep Çolak for commenting on the data and sharing their judgements with me. I am grateful to the audience of the Tu+6 Workshop and the reviewers for their insightful comments and feedback. Author: Hande Sevgi, Harvard University (handesevgi@ g.harvard.edu).
} 
However, there are crucial syntactic and semantic differences between VDbl in (1) and these structures in (2) and (3). I argue that VDbl in Trabzon dialect shows structural similarities with verb doubling phenomena in other languages rather than just carrying archaic Turkic properties. Before proposing an analysis for the structure, I present the properties of VDbl in the next section.

\section{Properties of VDbl in Trabzon dialect.}

2.1. MORPHOSYNTACTIC PROPERTIES. VDbl in Trabzon dialect involves two verbal elements:

Context: A: What happened to her? Did she have a car accident?

B: She just fell down.

Düş-me düş-tü.

fall-MA fall-PST.3SG

'She fell down.'

As the example illustrates, this structure consists of a verb that is fully inflected for tense, person, and number, as well as the identical verb stem which is combined with the morphological marker -mA. It is possible to form VDbl with any verb type (i.e., unaccusative, unergative, (di)transitive) and with any event type (i.e., stative, eventive), without any constraints:

Context: A: Are you going to rent this house?

B: We are going to buy it.

$\mathrm{Bu}$ ev-i al-ma al-aca(k)-1z.

DEM house-ACC buy-MA buy-FUT-1PL

'We are going to buy this house.'

However, we observe some constraints on the left constituent of the VDbl structure which bears the suffix -mA (henceforth, the double). The first constraint is that negation cannot be marked on the double, shown in (6).

(6) a. Araba kay-ma kay-m(a)-1yor.

car.NOM slide-MA slide-NEG-PROG.3SG

'The car is not sliding.'

b. *Araba kay-ma-ma kay-m(a)-1yor.

car.NOM slide-NEG-MA slide-NEG-PROG.3SG

We observe a similar constraint with the ability marker -Abil which precedes the negation, shown in (7).

(7) Context: A: Do you know French?

B: I can read a text in French but I cannot write anything in French.

a. Oku-ma oku-yabil-iyor-um ama yaz-ma yaz-a-m1-yor-um. ${ }^{1,2}$

read-MA read-ABIL-PROG-1SG but write-MA write-ABIL-NEG-PROG-1SG

'I can read (it) but I cannot write (it).'

\footnotetext{
1 The ability suffix in Turkish shows suppletion when negated.

${ }^{2}$ As the data shows, it is possible to inflect a verb with the ability marker in Trabzon Turkish. Moreover, 'oku-yabilme' is a grammatical structure in this dialect when it is a nominal. However, this form yields ungrammaticality when it is the double of VDbl.
} 
b. *Oku-yabil-me oku-yabil-iyor-um ama yaz-abil-me yaz-a-m1-yor-um. read-ABIL-MA read-ABIL-PROG-1SG but write-ABIL-MA write-ABIL-NEG-PROG-1SG

Furthermore, we observe a slightly vague constraint with the valency changing markers in VDbl structures. The causative marker is obligatorily pronounced on both constituents of the structure as in (8) while the passive marker is optional on the double as in (9):

Kurabiyeler-i yap-*(tır-)ma yap-tır-d1-m.

cookies-ACC make-(CAUS-)MA make-CAUS-PST-1SG

'I made someone to bake the cookies.'

$\mathrm{Bu}$ elbise dik-(il-)me dik-il-di.

DEM dress.NOM sew-(PASS-)MA sew-PASS-PST.3SG

'The dress was sewn (by a tailor, it was not bought from a shop.)'

An interesting point related to (8) and (9) is that the speakers of Trabzon Turkish tend to interpret these sentences with a nonspecific agent reading while it is difficult (but not impossible) for them to introduce a causee for (8) and an oblique agent for (9). More interestingly, the introduction of a causee leads the speakers of the dialect to interpret the intended causee as a benefactive argument of the structure, as in (10).

??/* Oya'ya kurabiyeler-i yap-tır-ma yap-tır-d1-m.

Oya-DAT cookies-ACC make-CAUS- MA make-CAUS-PST-1SG

Intended: 'I made Oya bake the cookies.'

Interpretation of the speakers: 'I made someone bake the cookies for Oya.'

2.2. SYNTACTIC PROPERTIES. The constituents of VDbl occur immediately adjacent to each other; moreover, the double cannot be fronted in Trabzon dialect as in (11).

(11) Trabzon Turkish (Adapted from Brendemoen, 2002: 216)

*Bat-ma deniz-de bat-t1-k biz.

sink-MA sea-LOC sink-PST-1PL 1PL.NOM

Intended: 'We sank in the sea.'

However, the focus particles $d A$ ( ' $\approx$ too' in English) and bile (' $\approx$ even' in English) as well as the question particle $m I$ can occur between the constituents of $\mathrm{VDbl}^{3}$.

(12) Trabzon Turkish (Adapted from Brendemoen, 2002: 216)

Deniz-de bat-ma bile bat-t1-k biz.

sea-LOC sink-MA even sink-PST-1PL 1PL.NOM

'We even sank in the sea.'

This property of VDbl shows parallelism with the bare noun objects in Turkish: No intervening element is allowed between the verb and its complement bare noun object except for the focus particles bile and $d A$ as well as the question particle $m I$. Furthermore, the occurrence of VDbl yields ungrammaticality when the complement of the verb is a bare noun object:

\footnotetext{
${ }^{3}$ The occurrence of the focus particles bile and $d A$ which introduce a set of alternatives into the interpretation results in a change in the meaning of VDbl. The presence of these focus particles lessens the contrastive focus reading of the structure. However, we do not observe such a meaning change in the presence of question particle $m I$. This interesting interaction between these particles and VDbl should be investigated in further studies.
} 
a. Telefon-u sat-ma sat-t1-m. phone-ACC sell-MA sell-PST-1SG

'I sold the phone.'

b. *Telefon sat-ma sat-t1-m. phone sell-MA sell-PST-1SG

2.3.FOCUS RELATED PROPERTIES. The interpretation provided by the speaker of this dialect indicates that this structure contributes a contrastive meaning to the structure. Moreover, we observe that the double in the VDbl constructions receives stress, which leads us to consider classifying this structure as a focus element, namely contrastive focus, since stress is the one and only indicator of focus in Turkish ${ }^{4}$ (Göksel \& Özsoy, 2000).

(14) Koş-MA koş-tu-k.

run- MA run- PST-1PL

'We ran.'

Based on these prominent properties presented in this section, we now move on to discuss the potential arguments related to the nature of this structure in the following section.

\section{Bringing the pieces together.}

The morphosyntactic properties of VDbl and the constraints on the double might indicate the hierarchical structure of this constituent. The absence of the negation and the modality marker on the double suggests that the operation related to the verb doubling happens in a stage early in the generation of the verbal projection, preceding negation and modality inflection.

Moreover, the similarity between VDbl and bare noun objects as well as their complementary distribution raises the question whether these two structures share the same position in the structure. Akdemir (2004) claims that bare noun objects form a complex predicate with the verb before any syntactic computations. Therefore, bare noun objects do not occupy a syntactic argument position (p. 472). Furthermore, Akdemir (2004) indicates that complex predicate formation is productive in Turkish. Cognate object verb structure, which posit similar structural properties to VDbl are exemplified in (15).
a. yaz-1 yaz-mak
b. ör-gü ör-mek
c. dik-iş dik-mek
write-DER.SUF ${ }^{5}$ write-INF
'to write'
knit-DER.SUF knit-INF
'to knit'
sew-DER.SUF Sew-IN
'to sew'

At this point, it is plausible to raise the question whether the double of VDbl occupies a syntactic position in the structure as these cognate object verb structures or not. A quick comparison of these structures illustrates the difference:

\footnotetext{
${ }^{4}$ Contra previous studies on the prosodic properties of Turkish, Gürer (2014) reveals that there is no statistical difference between contrastive focus, discourse new constructions, and broad focus constructions with respect to f0 measurements and duration measurements.

5 The derivational suffixes that derive the 'cognate objects' nominalize the verbal items. There are different derivational suffixes as illustrated in the examples.
} 
a. Bora bu etekler-i dik-ti.

Bora.NOM DEM skirts-ACC sew-PST.3SG

'Bora sewed these skirts.'

b. VDbl in Trabzon Turkish

Bora bu etekler-i dik-me dik-ti.

Bora.NOM DEM skirts-ACC sew-MA sew-PST.3SG

'Bora sewed these skirts (he did not buy them).'

c. Cognate object verb structure

*Bora bu etekler-i dik-iş dik-ti.

Bora.NOM DEM skirts-ACC sew-DER.SUF sew-PST.3SG

VDbl allows the presence of a direct object; however, cognate objects block any direct object in the structure. This indicates that cognate objects are the syntactic argument of a verb while the double of VDbl is not ${ }^{6}$.

The distribution of bare noun objects and VDbl as exemplified in (13a) and (13b) leads us to investigate whether focus is a relevant phenomenon for VDbl structures. For Dutch, Zwart (1997) shows that definite objects indicate the known information; therefore, they are not in focus. The indefinite objects tend to indicate new information; therefore, they are generally in focus (p. 94). We observe a similar pattern in Turkish: The definite objects which receive the accusative case marker tend to indicate the known information while the bare noun objects tend to indicate new information. Furthermore, when focused, the definite objects can contribute contrastive reading to the structure:

EV- İ al-d1-m.

house-ACC buy-PST-1SG

'I bought the flat (not the shop).'

This fact might be an explanation for the distribution of bare noun objects and VDbl in Trabzon Turkish. The example in (18) is a grammatical sentence while (19), in which the direct object is focused, is ungrammatical for Trabzon Turkish speakers.

(18) Ev-i al-ma al-d1-m, kirala-ma-d1-m. house-ACC buy-MA buy-PST-1SG rent-NEG-PST-1SG 'I bought the flat, I did not rent it.

*EV- İ al-ma al-d1-m, kirala-ma-d1-m. ${ }^{7}$ house-ACC buy-MA buy-PST-1SG rent-NEG-PST-1SG Intended: 'I bought THE FLAT, I did not rent it.'

\footnotetext{
${ }^{6}$ This fact is further confirmed by the argumenthood tests for the cognate objects indicated in Akkuş \& Öztürk (2017) such as pronominalization and the ability to take possessive.

${ }^{7}$ The sentence is ungrammatical even when the second conjunct provides the intended information about the contrast as in the following example:

* EV- İ al-ma al-d1-m, dükkan-1 değil. house-ACC buy-MA buy-PST-1SG workplace-ACC NEG Intended: 'I bought THE FLAT, not the workplace.'
} 
I argue that the ungrammaticality in (19) indicates that the contrastive focus position is already occupied by VDbl. Moreover, Trabzon dialect does not allow for a second focus position, either presentational or contrastive, which indicates that there is a fixed number and a fixed position for focus in Trabzon dialect which results in the observed VDbl cases.

In order to understand the structural difference between Turkish and Trabzon Turkish, any work on focus properties of Turkish might be helpful. Previous studies claim that the focus position immediately precedes the verb in Turkish (Kennelly 1997, among others). However, Göksel and Özsoy (2000) claim that sentential (syntactic) stress and focal stress are distinct properties in Turkish. The immediate preverbal position is for sentential stress in general while the focus phrases can receive the relevant stress either in-situ or in other positions in the focus field rather than having a fixed position in the structure. Moreover, based on the fact that stress can be assigned to any preverbal constituent, Göksel and Özsoy (2000) argue that the surface syntax of Turkish does not have a designated focus position and it is not clear how the representation of the focus field is derived from a syntactic level of representation.

Şener (2010), however, argues that there are syntactic structures related to focus and topic based on the presence of the topic and focus related morphemes in other languages such as Japanese. Furthermore, he proposes that no focus element moves in Turkish, either overtly or covertly, while it is the non-focus element(s) that moves to the peripheries. In line with Şener's (2010) work, İşsever (2003) indicates that presentational focus must occur in the preverbal position while contrastive focus does not have to be in the immediately preverbal position.

The previous examples of VDbl indicate that Trabzon Turkish differs from Turkish with respect to focus related properties since there is a fixed position for contrastive focus when the structure occurs.

4. Similar structures in literature. As indicated in the previous sections, VDbl involves two identical verbal elements. This property of the structure resembles [VV] converbs as in (20) and the doubled verbs (21) in standard Turkish

(20) Standard Turkish (Y1ld1z, 2014:1)

[Yaz-a yaz-a] ezberle-di-m.

write-OPT write-OPT memorize-PST-1SG

'I memorized (it) by writing and rewriting (it).'

(21) Standard Turkish (Erbaş1, 2015:2)

Kitab-1 [oku-du-lar oku-du-lar] bitir-e-me-di-ler.

book-ACC read-PST-3PL read-PST-3PL finish-ABIL-NEG-PST-3PL

'They kept reading the book (but still) they could not finish (it).'

Y1ldiz (2014) proposes that [VV] converbs in Turkish are productive co-compounds generated by a reduplication process. She claims that the syntax is the ultimate tool to explain the properties of this structure since '[VV] converbs can take their own complements and/or adjuncts even though they are adverbs' (p.179). Erbaş1 (2015) proposes that doubled verbs are generated by reduplicating the finite verbs. The doubled verb structure functions as an adverb which occurs below TP (p.112).

The common property of these two structures and VDbl in Trabzon Turkish is the repeated verbal constituent. However, the examples (20) and (21) show that the reduplicated verbal stems in [VV] converbs and in doubled verbs are conjugated by the identical morphological suffixes while the constituents of VDbl bear distinct suffixes. Moreover, the identical verbal elements in $[\mathrm{VV}]$ converbs and in doubled verbs constitute a phrasal category which functions as an 
adverbial modification for the main verb within the structure. The verbal elements do not depend on the main verb morphologically or phonologically. However, there is a tight dependency between the constituents of VDbl while these constituents present morphological differences which might indicate each constituent is subject to different operations within the structure (22).

(22) VDbl in Trabzon Turkish

[Makale-ye bak-ma bak-t1-m], [derinlemesine oku-ma-d1-m]. article-DAT look-MA look-PST-1SG thoroughly read-NEG-PST-1SG 'I just skimmed the article; I did not read it thoroughly.'

Based on these differences, I suggest that VDbl is not a simple case of a syntactic reduplication which results in compounding. Another relevant structure for our discussion is shown in (23):

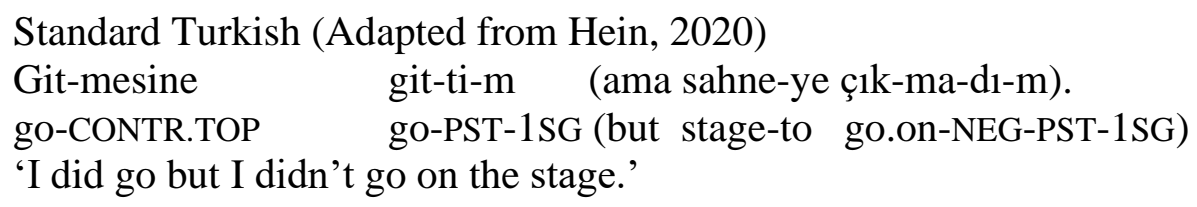

Similar to VDbl in Trabzon dialect, the structure in (23) consists of a finite verb associated with an identical verbal element. This verbal element is conjugated with the suffix -mAsInA which has been analyzed as one morpheme (cf. Göksel \& Kerslake, 2005). However, it is plausible to argue that the suffix can be decomposed into different morphemes, i.e., the suffix $-\mathrm{mA}$, the possessive suffix -sI(n), and -A which might be considered as a dative suffix. Such a decomposition makes clearer the relation between VDbl and the -mAsInA structure. Moreover, as indicated in the glosses, Hein (2020) analyzes the structure as a contrastive topic and considers this structure as an instance of verb doubling.

Despite these similarities, the structure has a different reading than VDbl. It contributes an 'abortive 'meaning to the action (Göksel \& Kerslake, 2005: 410). Moreover, there is an important syntactic distinction between the -mAsInA structure and VDbl: The finite verb and the other constituent may occur in different ordering in -mAsInA structure while the constituents of VDbl have fixed position and it is not possible to have different orderings of these items (24).
a. Git-tim
git-mesine
(ama sahne-ye çık-ma-d1-m). ${ }^{8}$
go-PST-1SG go-CONTR.TOP (but stage-to go.on-NEG-PST-1SG)
'I did go but I didn't go on the stage.'
b. *Yürü-dü-m yürü-me. walk-PST-1SG walk-MA

As Hein (2020) mentions, there is no prominent analysis of -mAsInA structure despite the fact that Turkish is not an underresearched language. Moreover, converbs and doubled verbs in Turkish have been analyzed as compounds which are the results of a reduplication process (Y1ld1z, 2014; Erbaş1, 2015) as mentioned above. Even though there are crucial differences between these structures and VDbl, it is not trivial to question whether a similar analysis, i.e., compounding, can be applicable to this structure. Due to the semantic and structural properties of VDbl, I investigate whether this structure is an instance of identical constituent compounding.

\footnotetext{
${ }^{8}$ There is no difference in meaning between (23) and (24a) despite their different word orders.
} 
Hohenhaus (2004) defines this type of compounding as 'the compounds whose two elements are the same' (p.299). The famous examples of this compounding are 'nap-nap 'and 'jealous-jealous ' which emphasize a prototype reading of 'nap 'and 'jealous '(p.300). 'Nap-nap', for example, denotes a real nap rather than 'a cat nap 'or 'a sofa nap.'

Even though the identical constituent compounding shows some similarities with VDbl, it is crucial to note that compounding, by its nature, does not allow any intervening elements between their constituents. However, the focus particles and the question particle can intervene between the constituents of VDbl as indicated in the previous sections, exemplified again in (25).

(25) Trabzon Turkish (Brendemoen, 2002: 225)

Araba-yla gid-iyor, yürü-me de yürü-mü-yor.

car-COM go-PROG.3SG walk-MA dA walk-NEG- PROG.3SG

'He goes (everywhere) by car, he does not go anywhere on foot.'

Thus, I argue that VDbl is not a result of compounding. Nonetheless, we cannot ignore the similarities between the semantic properties of the identical constituent compounding and those of VDbl in Trabzon dialect. For example, both structures involve one constituent that is modified by the 'identical 'constituent to emphasize the expression. Ghomeshi et al. (2004) investigate the same 'compound structures 'discussed in the work of Hohenhaus (2004). They suggest an account within the framework of Minimalist Program (Chomsky, 1993) and they argue that these structures are the result of a contrastive focus reduplication process. Due to the semantic similarity between two structures, I investigate whether VDbl is an instance of contrastive focus reduplication process.

Ghomeshi et al. (2004) argue that the occurrence of the identical verbal element in the contrastive focus reduplication structure, introduced by a contrastive focus reduplication phrase, is related to the spell-out process of the head and tail of a chain that is created due to the head movement (p.347). Following Rizzi (1997) and Kiss (1998), they argue that the structure has the feature [+contrastive topic] which triggers the movement. The occurrence of two identical constituents is due to the pronunciation of both copies at PF, which exist simultaneously in the structure according to the copy theory of movement (Chomsky, 1995). Ghomeshi et al. (2004) further suggest that the reason for the pronunciation of both copies is the derivational properties of contrastive focus reduplication process.

Similarly, Bross and Fraser (2020) investigate the contrastive focus reduplication structures. They propose that contrastive focus reduplication is the result of a movement to the specifier of Focus Phrase within the structure. This movement occurs cyclically; this cyclicity blocks any modification of the relevant constituents, as in (23).
a. I want a coffee-coffee
b. *I want a (*black/free/hot) coffee-coffee.

The same constraint applies to the contrastive focus reduplication of verbal elements. Bross and Fraser (2020) argue that the cyclic movement targets the specifier of Focus Phrase which is dominated by TP. In a similar way, the modification of the relevant constituent is ruled out:

German (Bross and Fraser 2020)

*Sollen wir heute gemütlich kochen-kochen? ${ }^{9}$

\footnotetext{
${ }^{9}$ Bross and Fraser (2020) indicate that only non-inflected verbs and modal verbs can undergo contrastive focus reduplication in German. They further argue that this implies that contrastive focus reduplicated verb moves into a
} 
Should we today comfortable cook-cook

Intended: 'Should we prepare a real meal comfortably today?'

We observe a similar modification constraint in VDbl:
a. Standard Turkish
Hizlıca yürü-dü-m.
fast walk-PST-1SG
'I walked fast.'
b. Trabzon Turkish
*Hızlıca yürü-me yürü-dü-m.
fast walk-MA walk-PAST-1SG
Intended: '(I did not run), I did walk fast.'

These examples support the idea that VDbl is related to contrastive focus. However, we observe structural differences between VDbl and contrastive focus reduplication accounts as in the case of identical compounding account. As pointed out by Ghomeshi et al. (2004), the presence of different morphological marker on the constituents are not easy to explain via the provided Minimalist account. However, an account in line with Distributed Morphology (Halle \& Marantz, 1993) where morphology is a post-syntactic component might be relevant as indicated by Ghomeshi et al. (2004).

Another related phenomenon is predicate cleft. This structure involves a verb doubling and a VP/V fronting process, exemplified in the Hebrew (29) and Yiddish (30).

Hebrew (Landau, 2006)

liknot, hi kanta et ha-praxim.

to-buy she bought ACC DEM-flowers

'As for buying, she bought the flowers.'

Yiddish (Bleaman, 2021)

red-n mame-loshn red ikh (*mame-loshn).

speak-INF mama-language speak.1SG I (*mama-language)

'As for speaking Yiddish, I speak it.'

Landau (2006) argues that verb doubling and VP/V fronting in Hebrew occur to fill the syntactic requirements. These requirements are for an argument to move into a focus position in the left periphery of the clause and to express finiteness at the same time. Moreover, Landau (2006) claims that this structure provides insights about the chain resolution process since two chain positions visible at $\mathrm{PF}$, one in the base position and one in the fronted position of a single chain, are decided to be pronounced (or to be deleted) at PF depending on 'the notion of precoverability.' In the case of verb doubling, two copies are pronounced since both chain positions require different phonological properties (of $\mathrm{T}^{0}$ and $\mathrm{Top}^{0}$ in Hebrew). Landau (2006) further argues that the different morphological marking on the constituents is due to the absence of tense and/or agreement features on the higher copy. Hence, the higher copy bears an infinitive marker which is the default spell-out form.

TP-internal focus position. However, we do not observe a similar constraint in VDbl; on the contrary, VDbl targets the main verb of the sentences which is inflected with TAM markers. 
These previous works and examples from different languages show that VDbl in Trabzon dialect shares some properties with these structures. However, we also observe that there are crucial differences between these structures and VDbl. In the light of the observations presented in the previous sections, I argue that VDbl carries a contrastive focus, which involves the selection of a subset out of a set of alternatives. The doubled verb in VDbl does not behave as a true argument unlike the cognate object structures. Moreover, the constituents of the structure bear different morphological markers unlike the instances of identical constituent compounding and contrastive focus reduplication. Finally, VDbl in Trabzon dialect does not show any verb fronting processes unlike the instances of predicate cleft in Hebrew and Yiddish. Based on these observations, I present a representation of this structure in the next section.

5. How to analyze VDbl in Trabzon Turkish? The immediate adjacency of the constituents of VDbl as well as the constraints on the double are the crucial part of this analysis. In order to account not only for the adjacent nature of the constituents and but also the absence of negation and TAM markers on the double, I claim that Trabzon dialect has an internal focus position above $\nu \mathrm{P}$ and dominated by NegP/TP, following the identificational focus of Kiss (1998) as well as Şener's (2010) analysis of contrastive focus in Turkish. This low focus phrase is a verbal focus position which is contrastive focus phrase (henceforth, CFP). I argue that the structure is as shown in (31)

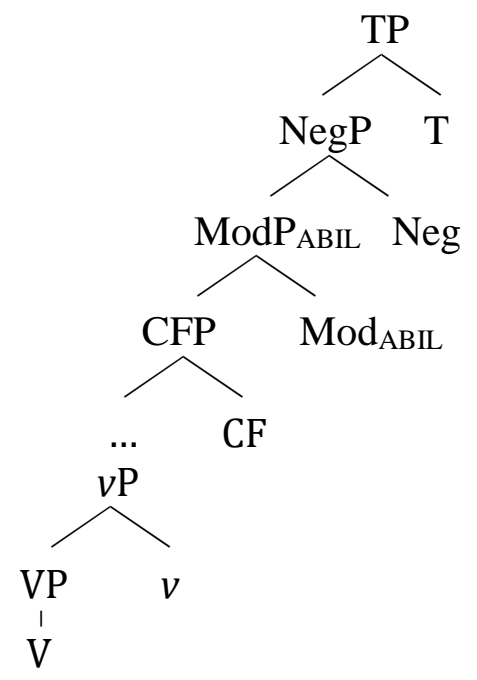

Following the assumption within the Minimalist framework that any movement occurs with the purpose of feature checking, I argue that CFP has the contrastive focus feature which triggers the movement of the verb phrase to its specifier position.

At this point, I follow the analysis of Harizanov and Gribanova (2017) on predicate fronting, verb raising, and object shift cases as well as their interactions in Russian ${ }^{10}$. Russian, among other languages, presents a complex picture of verb doubling since there are cases in which verb doubling occurs while object doubling is not attested:

\footnotetext{
${ }^{10} \mathrm{VDbl}$ in Trabzon dialect, on the other hand, does not present any solid evidence whether only the verb undergoes doubling or VP undergoes doubling while one of the object copies is deleted. However, I will continue following this analysis by Harizanov and Gribanova (2017).
} 
(32) Russian (Harizanov \& Gribanova, 2017)

Dumat' o ženit'be on dumaet.

think.INF about marriage he think.PRES.3SG

'He thinks about marriage.'

In order to account for the data similar to (32), Harizanov and Gribanova (2017) propose that there are two movement types: syntactic and post-syntactic movement.

Harizanov and Gribanova (2017) argues that syntactic operations are processes of internal merge. They yield non-distinct copies in the structure and these operations have semantic effects. On the other hand, post-syntactic operations are the process of morphological merge which does not yield any copies and they do not have any semantic effect on the structure.

Following the analysis of Harizanov and Gribanova (2017), I propose that VDbl in Trabzon dialect is the result of these two different movements. In Trabzon Turkish, $v \mathrm{P}$ moves to the focus position via syntactic movement motivated by the internal focus phrase. This syntactic movement to the specifier position of the contrastive focus phrase creates two 'non-distinct ' copies of the movement element. As represented in (33), $v \mathrm{P}_{1}$ moves to the specifier position of contrastive focus phrase. This new copy in the specifier position is represented as $v \mathrm{P}_{2}$.

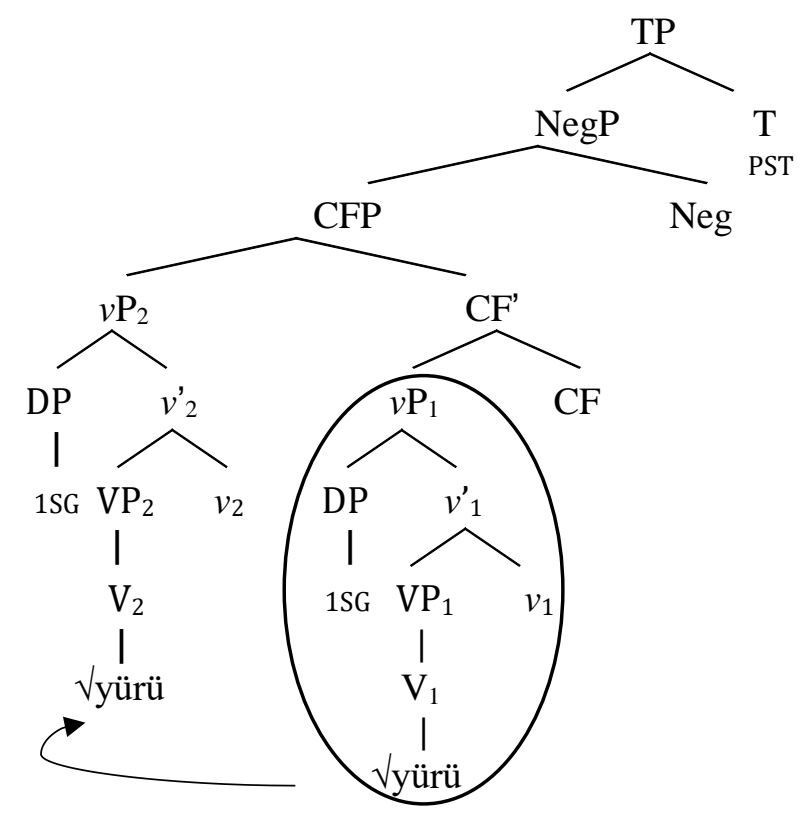

This syntactic movement has semantic effects on the structure. The post-syntactic movement, on the other hand, does not create any copies and it does not have any semantic effect on the structure. It functions as a morphological merge as in (34). 


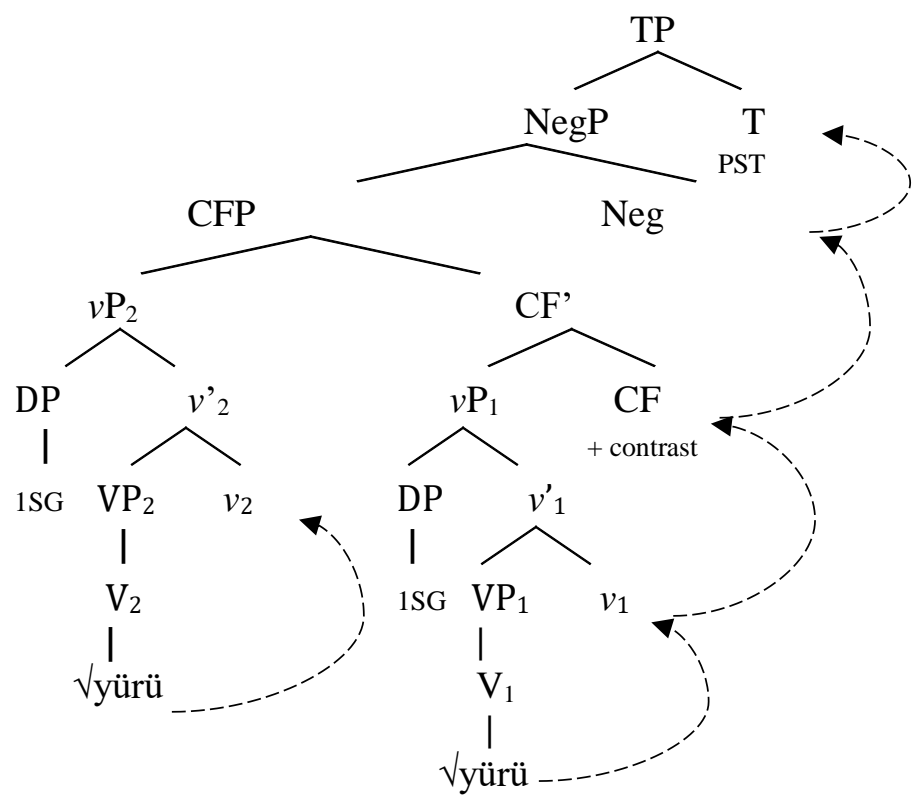

The original copy which is yürü 'walk' undergoes head movement up to T.

Finally, the output of the post-syntactic movement undergoes a final chain reduction. During the final chain reduction, the head of the chain and the terminals contained in the head are pronounced. However, the foot of the chain and the terminals contained in the foot are not pronounced. This reduction rule yields the structure in (35) since the head of chain $v \mathrm{P}_{2}$ is pronounced while the foot of the chain $v \mathrm{P}_{1}$ is deleted.

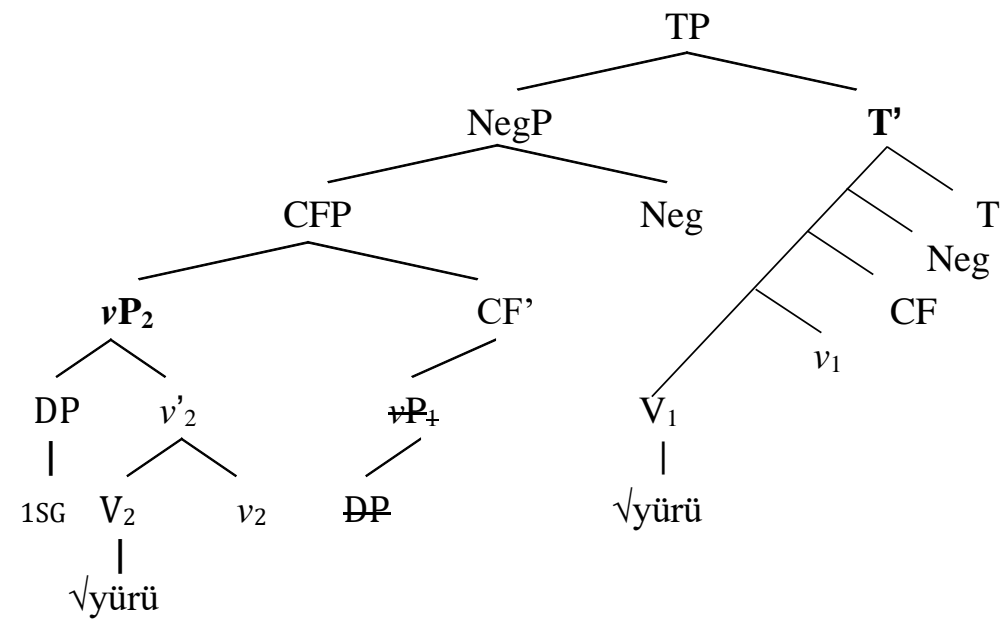

There remains an important question in this structure: Why is there a morphological marker -mA on the double? For Hebrew, Landau (2006) argues that presence of morphological marker on the constituent is a result of a post-syntactic repair operation which takes place to meet morphosyntactic requirements of the structure. In Hebrew, the double moves to a higher position than $\mathrm{T}^{0}$; therefore, the verbal copy cannot be inflected with any TAM markers and, as a result, it receives the default form which is an infinitival marker. As (35) indicates, both the double and the original copy occur lower than $\mathrm{T}^{0}$. Based on the other examples of VDbl in Trabzon Turkish, I assume this marker is also an infinitival marker which can be the default form in this dialect. It is possible that CFP prevents any kind of inflection via $\mathrm{T}^{0}$. Since the verbs are bound roots and 
they require to be inflected to be pronounced, the morphological marker $-\mathrm{mA}$ attaches to the double. Nonetheless, these are assumptions which do not have solid evidence; therefore, the nature of the morphological marker and the mechanism behind it should be investigated in the future research.

5. Conclusions and remarks. In this paper, I provide a description of the properties of verb doubling structures in Trabzon Turkish. Based on these descriptive properties, I claim that Trabzon Turkish has a fixed syntactic contrastive focus position which is dominated by $\operatorname{Mod}_{\mathrm{ABII}} / \mathrm{NegP} / \mathrm{TP}$. I further argue that this structure can be analyzed as the result of two different movement processes.

Following Landau (2006), I argue that there is a repair operation to satisfy the requirements of the structure in order to account for the presence of the suffix -mA on the double of VDbl. However, neither the syntactic properties of this suffix nor the reason of the need for the suffix $\mathrm{mA}$ but not any other suffixes is clear. For the time being, I assume that this is an infinitival suffix as it is the case for the other languages discussed in the literature.

Another interesting question is what blocks the presence of verb doubling structure in the environment of contrastive focus in Standard Turkish but not in Trabzon dialect.

Trabzon Turkish

Annem bu kazak-lar- $\iota$ ör-me ör-dü. mother-1SG.POSS DEM sweater-PL-ACC knit-MA knit-PST.3SG

'My mother KNITTED these sweaters, (she did not buy them).'

(37) Standard Turkish (Kelepir, 2001:111)

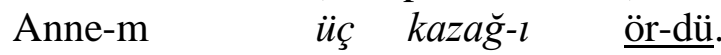

mother-1SG.POSS three sweater-ACC knit-PST.3SG

'My mother KNITTED these sweaters, (she did not buy them).'

As (37) illustrates, the contrastive focus in Turkish is realized with the stress on the verb while we observe a verb doubling process in Trabzon Turkish. Şener (2010) proposes that movement operations in Turkish are driven by discourse-based features. Moreover, focus-phrases and whphrases stay in-situ while non-focus phrases move within the structure. I argue that Şener's (2010) proposal might explain the attested difference between Standard Turkish and Trabzon Turkish. Since the focus element which is the verb in this case cannot move to a focus position, it can only indicate this property via stress while Trabzon dialect enables the movement of the verb to a focus position. However, detailed research on the information structure of Trabzon Turkish is necessary for a decent explanation.

It is also important to note that this data in Trabzon Turkish might give a better understanding of the nature of the pronunciation of both copies in contrastive focus reduplication structures and verb doubling phenomena. However, within the scope of this paper, I only attempt to explain the phenomena in Trabzon Turkish, and leave these crucial questions for further investigations.

Finally, VDbl structure in Trabzon dialect needs to be investigated in the light of language contact since Trabzon has been home for different languages including Romeika (Pontic Greek) and Laz, among others. A study which includes and compares these languages might enable us to understand this phenomenon and the components of the structure. 


\section{References}

Akdemir, Yasemin. 2004. Are Turkish preverbal bare nouns syntactic arguments?. Linguistic Inquiry, 35(3). MIT Press. 465-474. https://doi.org/10.1162/0024389041402607.

Akkuş, Faruk, \& Öztürk, Balkız. 2017. On Cognate Objects in Sason Arabic. University of Pennsylvania Working Papers in Linguistics, 23(1). Proceedings of the 40th Annual Penn Linguistics Conference, UPENN.

Bleaman, Isaac L. 2021. Predicate fronting in Yiddish and conditions on multiple spell-out. Nat Lang Linguist Theory. https://doi.org/10.1007/s11049-021-09512-3.

Brendemoen, Bernt. 2002. The Turkish Dialects of Trabzon. Wiesbaden: Harrassowitz.

Bross, Fabian, \& Katherine Fraser. 2020. Contrastive focus reduplication and the modification puzzle. Glossa: a journal of general linguistics, 5(1), 47. 1-18. https://doi.org/10.5334/gjgl.1075.

Chomsky, Noam. 1993. A Minimalist Program for Linguistic Theory. MIT Occasional Papers in Linguistics, 1. Cambridge, Massachusetts: Distributed by MIT Working Papers in Linguistics.

Chomsky, Noam. 1995. The Minimalist Program, Cambridge, MA: MIT Press.

Coşar, Mevhibe. 2015. Bir Kimlik İşaretleyici Olarak Dil ve Trabzon Ağızlarında Arkaik Hususiyetler. The Journal of Institute of Blacksea Studies.1. 241-253.

Erbaş1, Betül. 2015. Inflected Doubled Verbs in Turkish (Unpublished Master's thesis). Boğaziçi University, Istanbul.

Ghomeshi, Jila, Ray Jackendoff, Nicole Rosen, \& Kevin Russell. 2004. Contrastive focus reduplication in English (the Salad-Salad paper). Natural Language and Linguistic Theory, 22(2). 307-357. https://doi.org/10.1023/b:nala.0000015789.98638.f9.

Göksel, Asl1, \& A. Sumru Özsoy. 2000. Is there a focus position in Turkish? In Aslı Göksel \& Celia Kerslake. (Eds.). Studies on Turkish and Turkic languages: Proceedings of the ninth international conference on Turkish linguistics. Wiesbaden, 219-228.

Göksel, Aslı \& Celia Kerslake. 2005. Turkish: A Comprehensive Grammar. London: Routledge. https://doi.org/10.4324/9780203340769.

Gürer, Asl1. 2014. Prosody of contrastive focus and discourse new constituents in Turkish. Dilbilim Araştırmaları Dergisi [Journal of Linguistics Research]. 1. 31-58.

Halle, Morris, \& Alec Marantz. 1993. Distributed morphology and the pieces of inflection. In Kenneth Hale \& Samuel Jay Keyser. (Eds.). The View from Building 20: Essays in Linguistics in Honor of Sylvain Bromberger. Cambridge: MIT Press. 111-176.

Harizanov, Boris, \& Vera Gribanova. 2017. Post-syntactic head movement in Russian predicate fronting. $91^{\text {st }}$ Annual Meeting of the LSA: Austin, TX.

Hein, Johannes. 2020. Verb Doubling and Dummy Verb. Berlin: De Gruyter. https://doi.org/10.1515/9783110635607.

Hohenhaus, Peter. 2004. Identical constituent compounding: A corpus-based study. Folia Linguistica, 38. 297-332. Berlin: Mouton de Gruyter.

https://doi.org/10.1515/flin.2004.38.3-4.297.

İşsever, Selçuk. 2003. Information structure in Turkish: the word order-prosody interface. Lingua, 113. 1025-1053

Kelepir, Meltem. 2001. Topics in Turkish Syntax: Clausal Structure and Scope. (Doctoral Dissertation). MIT, USA.

Kennelly, Sarah D. 1997. The presentational focus position of nonspecific objects in Turkish. In 
Kamile İmer \& Nadir Uzun (Eds.). Proceedings of the VIII ${ }^{\text {th }}$ International Conference on Turkish Linguistics. Ankara: Ankara University Press, 25-36.

Kiss, Katalin. 1998. Identificational focus versus information focus. Language, 74. 245-273.

Korkmaz, Zeynep. 2009. Türkiye Türkçesi Grameri Şekil Bilgisi. Ankara: Türk Dil Kurumu Yayınları.

Landau, Idan. 2006. Chain resolution in Hebrew V(P)-fronting. Syntax, 9(1). 32-66. https://doi.org/10.1111/j.1467-9612.2006.00084.X.

Öztürk, Balkız. 2005. Case, Referentiality and Phrase Structure. John Benjamin Press. https://doi.org/10.1075/la.77.

Rizzi, Luigi. 1997. The fine structure of the left periphery. In Liliane Haegeman (ed.). Elements of Grammar. Kluwer International Handbooks of Linguistics. Springer, Dordrecht. 281-337. https://doi.org/10.1007/978-94-011-5420-8_7.

Şener, Serkan. 2010. (Non-)Peripheral matters in Turkish syntax. (Doctoral Dissertation). UCONN, USA.

Yıldız, Esra. 2014. Reduplication as a Compounding Process: The Case Of [VV] Converbs in Turkish (Unpublished Master's thesis). Boğaziçi University, Istanbul.

Zwart, Jan-Wouter. 1997. Morphosyntax of Verb Movement. Kluwer Academic Publishers. https://doi.org/10.1007/978-94-011-5880-0. 